\title{
Thoracoscopic microsurgical excision of a thoracic schwannoma
}

\section{Case report}

\section{Curtis A. Dickman, M.D., and Ronald I. Apfelbaum, M.D.}

Division of Neurological Surgery, Barrow Neurological Institute, and Mercy Healthcare Arizona, Phoenix, Arizona; and Department of Neurosurgery, University of Utah, Salt Lake City, Utah

A 6-cm-diameter schwannoma located at T-2 was resected completely by using transthoracic microsurgical endoscopy. The partially cystic tumor widened the neural foramen and extended into the apex of the right thoracic cavity but did not extend intradurally. The tumor was accessed by means of three $15-\mathrm{mm}$ incisions made in the intercostal spaces. The operative blood loss was only $200 \mathrm{ml}$, and there were no complications. The patient was discharged on the 2 nd postoperative day and returned to full activity 1 week after surgery.

Thoracoscopy provides an excellent alternative to thoracotomy for peripheral thoracic nerve sheath tumors that originate within the neural foramen or more distally along the intercostal nerves within the thorax. An anterior approach is required for intrathoracic tumors but is not suited for intradural tumors. An open posterior or posterolateral approach to the thoracic spine is required for intradural tumors to allow the dura to be closed adequately.

Key Words * thoracoscopy * microsurgery * endoscopy * schwannoma * neurofibroma * thoracic spine * spinal tumors * video-assisted thoracoscopic surgery

The use of thoracoscopy has rapidly increased during the past decade and has been used to treat a wide array of pathological processes involving the thorax and mediastinum.[1,15,17] Thoracoscopy has also been applied successfully to a variety of spinal applications: sympathectomies, thoracic discectomies, corpectomies, spinal reconstructions and internal fixations, anterior releases to correct spinal deformities, decompressions of the spinal cord and nerve roots, stabilization of the thoracic spine, and to obtain biopsies of vertebral lesions.[3-6,10,11,18,19,22,23,24,26] We report a patient with a thoracic schwannoma that was resected by means of thoracoscopy in which microsurgical endoscopic techniques were used.

\section{CASE REPORT}

Examination. This 52-year-old woman presented for routine chest radiography to evaluate dyspnea and a productive cough and was found to have a right upper lobe mass. She had no neurological symptoms or signs, and the results of both her neurological and physical examinations were normal. There were no 
stigmata of neurofibromatosis.

Neuroimaging. A magnetic resonance (MR) imaging study of the thoracic spine (Fig. 1) demonstrated an enhancing, 6-cm-diameter cystic lesion arising from the right neural foramen of T-2. The tumor widened the neural foramen and extended widely into the apex of the right hemithorax. The tumor extended to the lateral edge of the dura but did not extend intradurally.

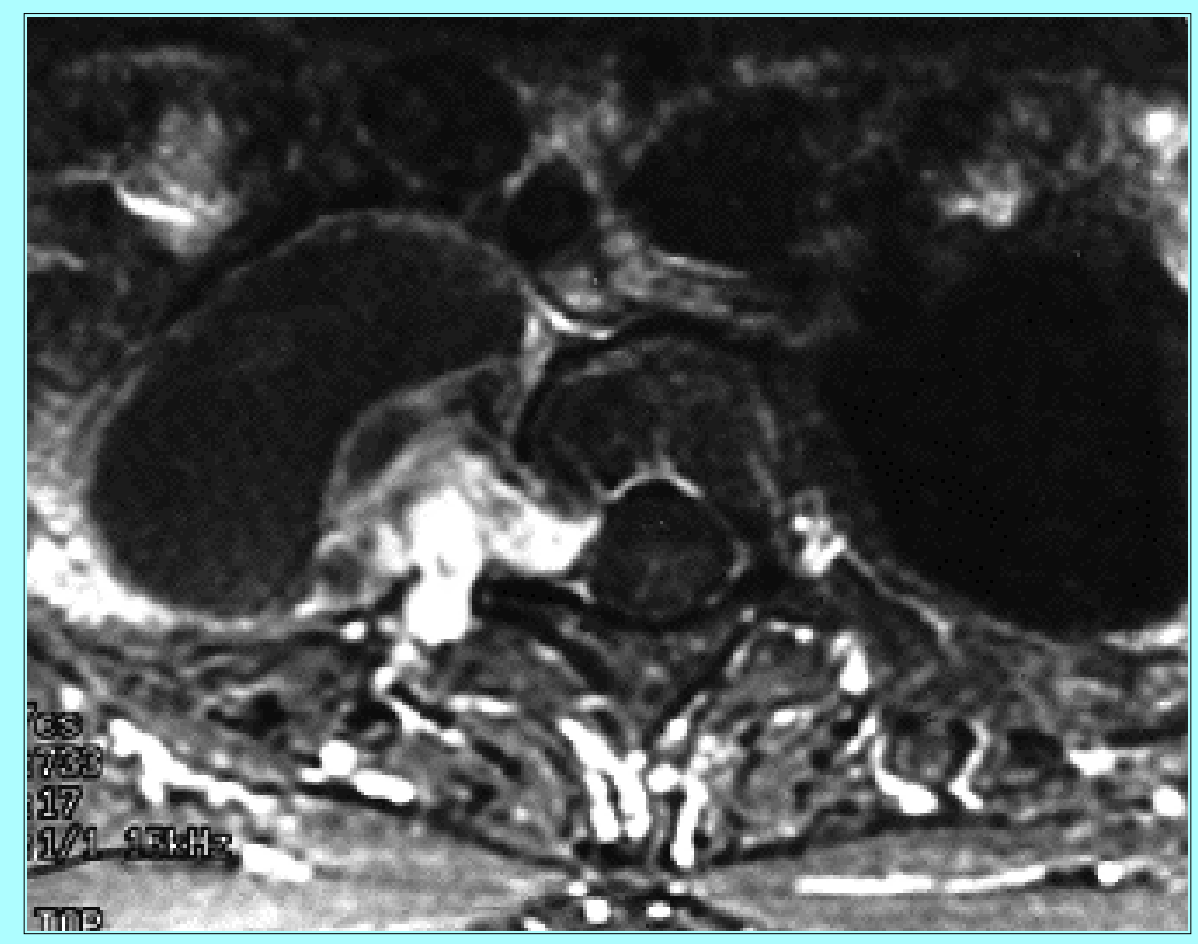

Fig. 1. Gadolinium-enhanced axial MR image showing that an enhancing tumor has widened the neural foramen at T-2 and extended into the chest. A 6 X 6-cm spherical cyst extends into the chest, but the tumor does not extend intradurally.

After 6 months of monitoring, the patient decided to undergo surgical removal of the tumor to prevent its further growth within the chest or into the spinal canal.

Operation. A double-lumen endotracheal tube was placed to allow intraoperative single-lung ventilation. The patient was placed in a left lateral decubitus position. Her right arm was abducted, elevated, padded, and secured to an ether screen to provide access to the axilla and anterolateral thorax. Three flexible 15-mm-diameter thoracoscopic portals were inserted into the third, fourth, and fifth intercostal spaces. One portal was used to insert a three-dimensional rod-lens endoscope; the other two portals were used to insert tools with which to perform the dissection.

The ventilation of the right lung was stopped and the lung became atelectatic, providing exposure of the chest wall, spine, and tumor within the thoracic cavity. The patient was rotated ventrally to allow gravity to retract the lung away from the spine. 


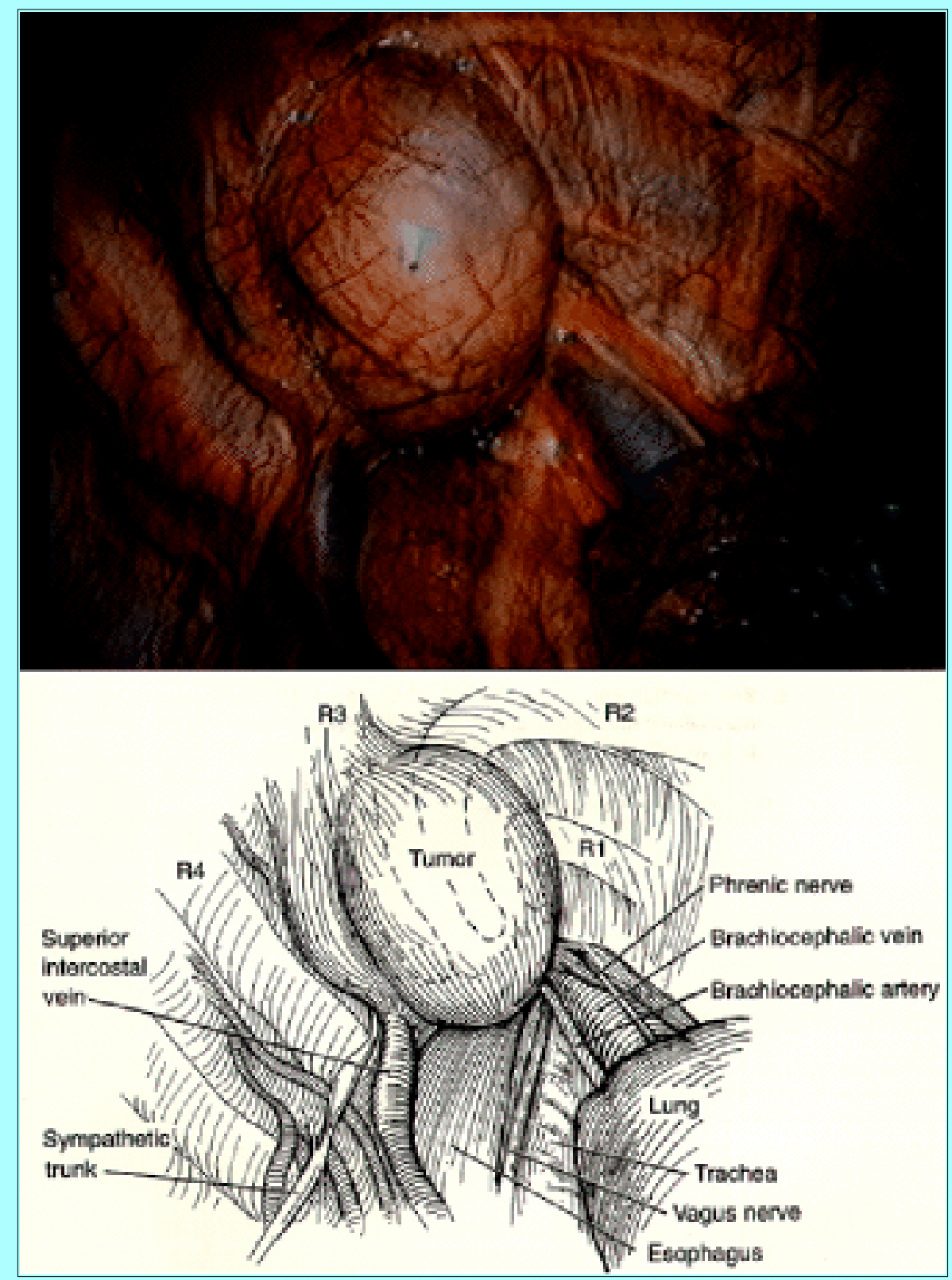

Fig. 2. Intraoperative photograph (A) and corresponding illustration (B) showing an endoscopic view of the tumor and the anatomy of the thoracic cavity from a right-sided thoracoscopic approach. The large cystic tumor, which extends from the T-2 neural foramen into the apex of the chest, is adjacent to the spine, chest wall, trachea, esophagus, brachycephalic and subclavian vessels, and the phrenic and vagus nerves. Top = rostral; bottom = caudal; left = lateral; and right $=$ medial .

The tumor and the adjacent vascular and visceral and musculoskeletal structures were clearly identified (Fig. 2). A needle was inserted into the cystic component of the tumor and $30 \mathrm{ml}$ of thin translucent xanthochromic fluid was aspirated from the tumor. The internal decompression of the tumor facilitated mobilization of the mass (Fig. 3). 


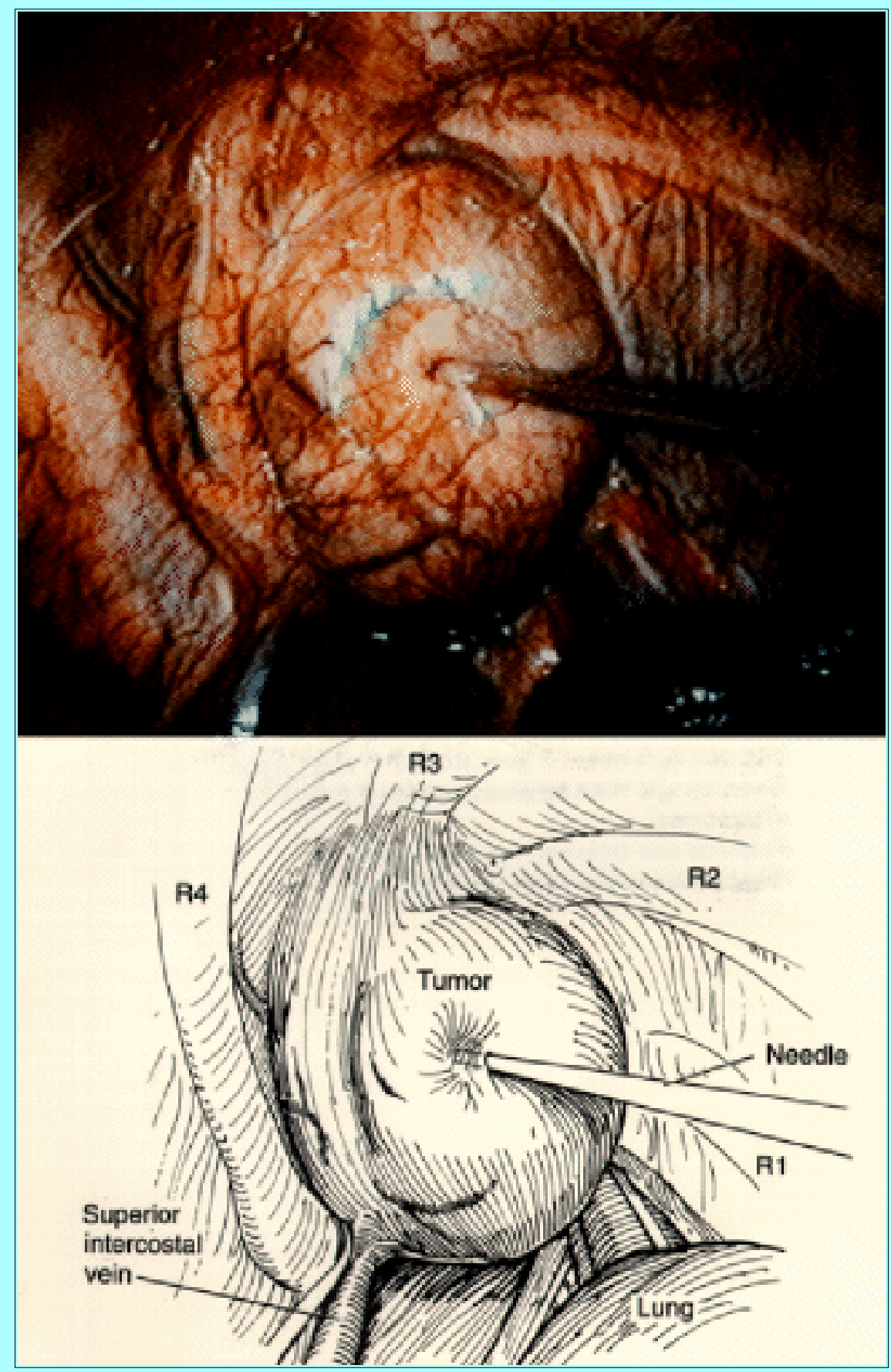

Fig. 3. Intraoperative photograph (A) and corresponding illustration (B) showing how the tumor cyst is decompressed by inserting a long needle into it and withdrawing $20 \mathrm{ml}$ of xanthochromic fluid.

The pleura overlaying the tumor was incised using an endoscopic microscissor and opened widely to mobilize the pleural margins from the tumor. The vascular supply to the tumor was coagulated with bipolar cauterization.

The tumor capsule was separated from the chest wall, adjacent vessels, and the mediastinum by using sharp and blunt dissection with endoscopic soft-tissue dissection tools (Fig. 4). The tumor was mobilized and followed to the surface of the spine and to the neural foramen. The intrathoracic tumor tissue was then excised in several pieces, which were removed from the chest through the endoscopic portal. The stump of tumor entering the neural foramen was shrunk with endoscopic bipolar cauterization to mobilize the foraminal component of the tumor. 


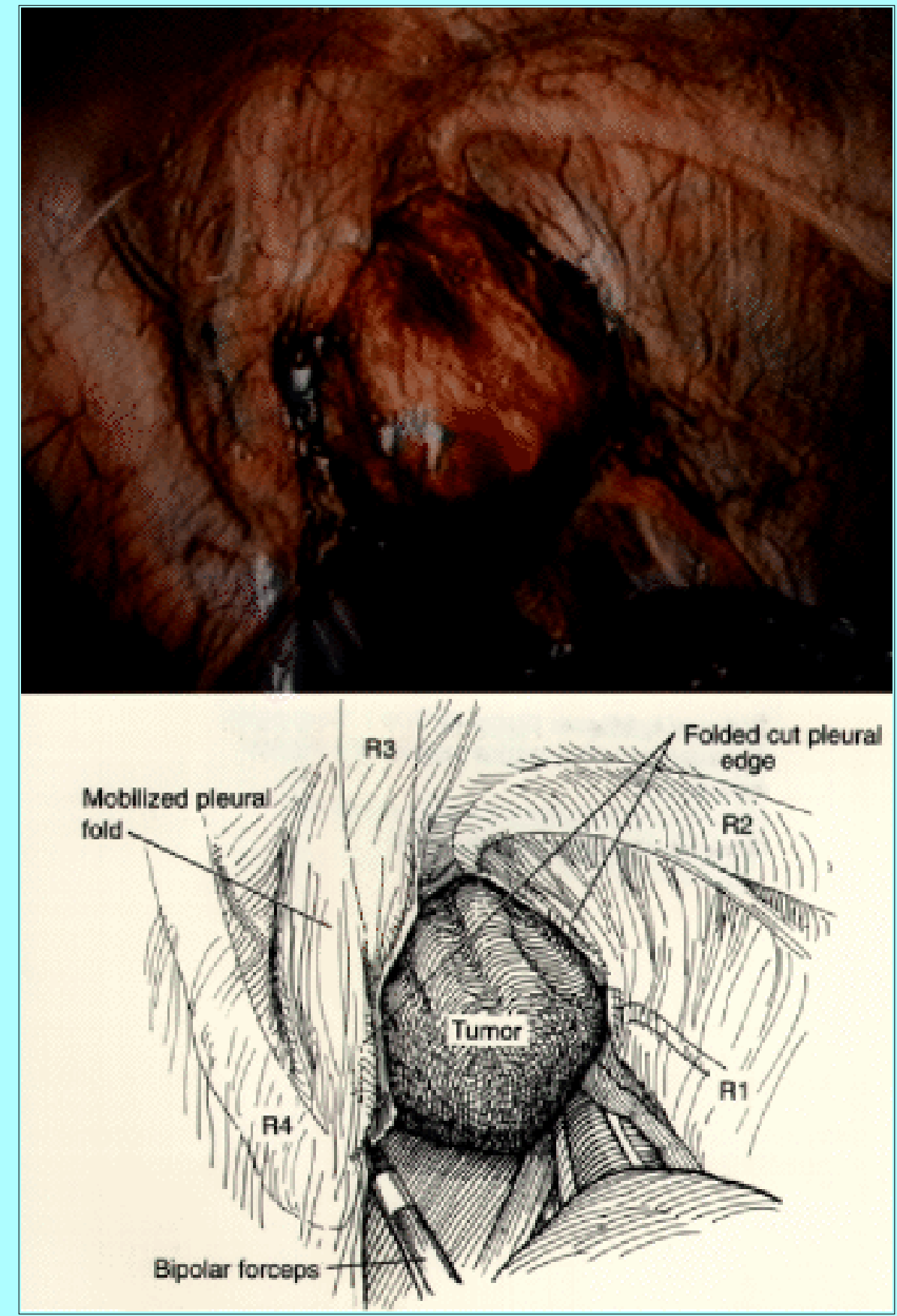

Fig. 4. Intraoperative photograph (A) and corresponding illustration (B) showing how the pleura is incised and dissected from the surface of the tumor to expose the tumor surface completely. The tumor is carefully separated from the adjacent vascular and visceral structures by using sharp and blunt dissection.

The epidural space and proximal nerve root sleeve adjacent to the tumor were identified by removing the head of the T-3 rib and the T-3 pedicle caudal to the tumor. This dissection was achieved with endoscopic rib dissectors, curettes, periosteal elevators, Kerrison rongeurs, and a pneumatic drill.

After the dura and proximal nerve root were identified, the root sleeve was ligated at its junction with the dura by using an endoscopic suture ligature (Fig. 5). The root was sectioned distal to the ligature, and the residual foraminal tumor was removed as a single piece. Hemostasis was achieved with bipolar cauterization and Avitene. A Valsalva maneuver was performed to verify that there was no cerebrospinal fluid (CSF) leak. 


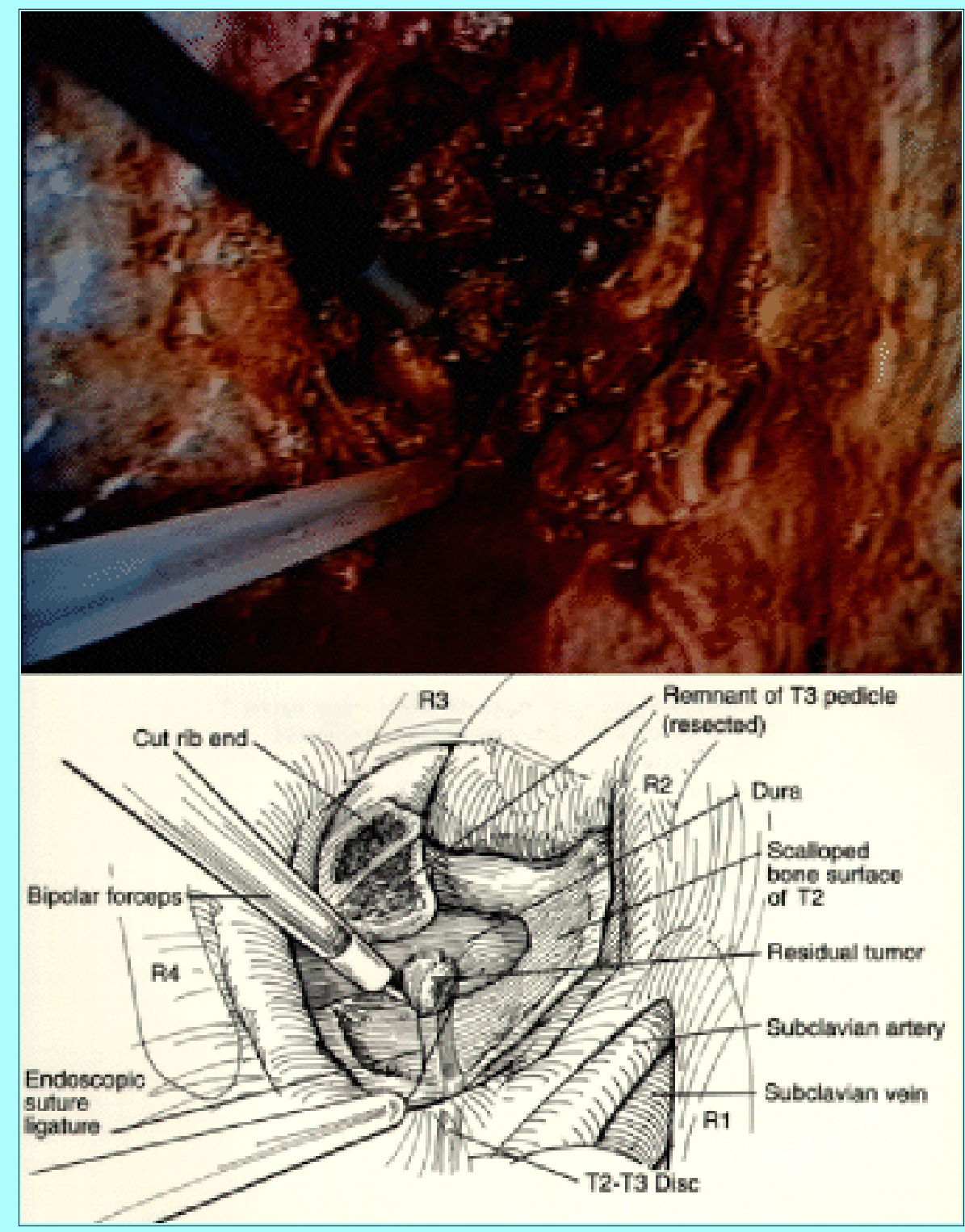

Fig. 5. Intraoperative photograph (A) and corresponding illustration (B) showing that the tumor has been resected. The foraminal component of the tumor was resected after the dura and proximal T-2 root sleeve was exposed by removing the T- 3 rib head and T-3 pedicle. Once the dura and proximal nerve root were identified, the proximal root was ligated with an endoscopic suture loop and the root was divided distal to the ligature. The distal nerve root and the residual tumor were then removed completely by using sharp dissection. Left $=$ inferior; right $=$ cephalad; top $=$ lateral; and bottom = medial .

Intraoperatively, a chest tube was placed through one of the endoscopic portals. The lung was inspected and reinflated under direct endoscopic visualization. The portals were removed and the three 15-mm incisions were closed with absorbable sutures. The duration of the procedure was 4 hours (from skin incision to closure) and the patient lost $200 \mathrm{ml}$ of blood.

Postoperative Course. Postoperatively, the patient remained neurologically intact. Her chest tube was removed on the 2 nd postoperative day (total fluid drainage was $300 \mathrm{ml}$ ). She had no postoperative complications and returned to full activity 7 days after the procedure.

\section{DISCUSSION}


Thoracoscopy provides an excellent alternative to a thoracotomy for resecting intrathoracic schwannomas or neurofibromas with large components within the chest cavity. Only four other cases in which thoracoscopy has been used to resect an intrathoracic nerve sheath tumor have been reported.[13,16,20,28] Thoracoscopy has also been used to resect mediastinal and vertebral body tumors. $[6,12,25]$

The tumors most amenable to thoracoscopic resection are those located peripherally within the intercostal nerves or that extend from the neural foramen into the chest. Presently, however, thoracoscopic resection is not advised for intradural extensions of tumor (for example, dumbbell tumors) because it is technically difficult to achieve a watertight dural closure by using endoscopic techniques. Intradural tumors should be resected through an open posterior or posterolateral approach to allow dural closure. If an anterior approach is also required to resect a large intrathoracic extension of a dumbbell tumor, the operative procedures can be staged. The intradural tumor is removed first and the dura is closed by means of a dorsal approach. The ventral approach (thoracoscopy or thoracotomy) is performed next to remove any intrathoracic portions of the tumor that are unaccessible by means of the posterior or posterolateral approach.

The surgical indications for the resection of an intrathoracic nerve sheath tumor include the need to obtain a tissue biopsy specimen for diagnosis, to prevent a malignant transformation, to relieve mass effect within the chest (for example, when pulmonary function is impaired), or to prevent the tumor from extending through the foramen into the spinal canal.[8,21,27]

The surgical techniques to resect these tumors are relatively simple. Careful mobilization of the tumor from the adjacent vascular and mediastinal structures is very impotant. Traction placed on the proximal tumor can cause avulsion of the nerve root, a CSF leak, or spinal cord damage, and this should be avoided. Once the tumor is fully mobilized, the bulk should be sharply resected. When the tumor extends into the neural foramen, bone dissection (rib and pedicle removal) is required to identify the epidural space and root sleeve clearly, to ligate the root and excise proximal tumor within the foramen, and to prevent a CSF leak.

The practice of thoracoscopic surgery requires dedication and training to learn the new psychomotor skills that are needed to perform these techniques safely. We strongly recommend that surgeons attend training courses and practice the surgical techniques in a laboratory setting, using animal and cadaveric models before attempting to use any of these techniques clinically.

Compared with thoracotomy, thoracoscopy requires much smaller incisions and is associated with better cosmetic results, less postoperative pain, fewer pulmonary complications, shorter hospitalizations, and an earlier return to activity.[2,3,6,7,9,14,19,22,24] Thoracoscopy is a viable alternative to thoracotomy for the resection of intrathoracic nerve sheath tumors.

\section{References}

1. Coltharp WH, Arnold JH, Alford WC Jr, et al: Videothoracoscopy: improved technique and expanded indications. Ann Thorac Surg 53:776-779, 1992

2. Dajczman E, Gordon A, Kreisman H, et al: Long-term postthoracotomy pain. Chest 99:270-274, 1991

3. Dickman CA, Karahalios DG: Thoracoscopic spinal surgery. Clin Neurosurg 43:392-422, 1996 
4. Dickman CA, Mican CA: Multilevel anterior thoracic discectomies and anterior interbody fusion using a microsurgical thoracoscopic approach. Case report. J Neurosurg 84:104-109, 1996

5. Dickman CA, Mican CA: Thoracoscopic approaches for the treatment of anterior thoracic spinal pathology. BNI Quarterly 12:4-19, 1996

6. Dickman CA, Rosenthal D, Karahalios DG, et al: Thoracic vertebrectomy and reconstruction using a microsurgical thoracoscopic approach. Neurosurgery 38:279-293, 1996

7. Ferson PF, Landreneau RJ, Dowling RD, et al: Comparison of open versus thoracoscopic lung biopsy for diffuse infiltrative pulmonary disease. J Thorac Cardiovasc Surg 106:194-199, 1993

8. Grillo HC, Ojemann RG, Scannell JG, et al: Combined approach to "dumbbell" intrathoracic and intraspinal neurogenic tumors. Ann Thorac Surg 36:402-407, 1983

9. Hazelrigg SR, Landreneau RJ, Boley TM, et al: The effect of muscle-sparing versus standard posterolateral thoracotomy on pulmonary function, muscle strength, and postoperative pain. J Thorac Cardiovasc Surg 101:394-401, 1991

10. Horowitz MB, Moossy JJ, Julian T, et al: Thoracic discectomy using video assisted thoracoscopy. Spine 19:1082-1086, 1994

11. Kao MC, Tsai JC, Lai DM, et al: Autonomic activities in hyperhidrosis patients before, during, and after endoscopic laser sympathectomy. Neurosurgery 34:262-268, 1994

12. Landreneau RJ, Dowling RD, Castillo WM, et al: Thoracoscopic resection of an anterior mediastinal tumor. Ann Thorac Surg 54:142-144, 1992

13. Landreneau RJ, Dowling RD, Ferson PF: Thoracoscopic resection of a posterior mediastinal neurogenic tumor. Chest 102:1288-1290, 1992

14. Landreneau RJ, Hazelrigg SR, Mack MJ, et al: Postoperative pain-related morbidity: Video-assisted thoracic surgery versus thoracotomy. Ann Thorac Surg 56:1285-1289, 1993

15. Landreneau RJ, Mack MJ, Hazelrigg SR, et al: Video-assisted thoracic surgery: Basic technical concepts and intercostal approach strategies. Ann Thorac Surg 54:800-807, 1992

16. Lyons MK, Gharagozloo F: Video-assisted thoracoscopic resection of intercostal neurofibroma. Surg Neurol 43:542-545, 1995

17. Mack MJ, Aronoff RJ, Acuff TE, et al: Present role of thoracoscopy in the diagnosis and treatment of diseases of the chest. Ann Thorac Surg 54:403-409, 1992

18. Mack MJ, Regan JJ, Bobechko WP, et al: Application of thoracoscopy for diseases of the spine. Ann Thorac Surg 56:736-738, 1993

19. McAfee PC, Regan JR, Zdeblick T, et al: The incidence of complications in endoscopic anterior thoracolumbar spinal reconstructive surgery. A prospective multicenter study comprising the first 100 consecutive cases. Spine 20:1624-1632, 1995

20. McNulty PS, McAfee PC, Regan JJ: Biopsy of discs, vertebral, and paraspinal masses, in Regan JJ, McAfee PC, Mack MJ (eds): Atlas of Endoscopic Spine Surgery. St. Louis: Quality Medical, 1995, pp 
21. Reed JC, Hallet KK, Feigin DS: Neural tumors of the thorax: Subject review from the AFIP. Radiology 126:9-17, 1978

22. Regan JJ, Mack MJ, Picetti GD III, et al: A comparison of video-assisted thoracoscopic surgery (VATS) with open thoracotomy in thoracic spinal surgery. Todays Ther Trends 11:203-218, 1994 23. Robertson DP, Simpson RK, Rose JE, et al: Video-assisted endoscopic thoracic ganglionectomy. J Neurosurg 79:238-240, 1993

24. Rosenthal D, Dickman C, Rudiger L, et al: Thoracic disc herniation: early results after surgical treatment using microsurgical endoscopy. J Neurosurg 84:334A, 1996 (Abstract)

25. Rosenthal D, Marquardt G, Lorenz R, et al: Anterior decompression and stabilization using a microsurgical endoscopic technique for metastatic tumors of the thoracic spine. J Neurosurg 84:565-572, 1996

26. Rosenthal D, Rosenthal R, de Simone A: Removal of a protruded thoracic disc using microsurgical endoscopy. A new technique. Spine 19:1087-1091, 1994

27. Shields TW, Reynolds M: Neurogenic tumors of the thorax. Surg Clin North Am 68:645-668, 1988

28. Weder W, Schlumpf R, Schimmer R, et al: Thoracoscopic resection of benign schwannoma. Thorac Cardiovasc Surg 40:192-194, 1992

Manuscript received August 12, 1997.

Accepted in final form January 2, 1998.

Address reprint requests to: Curtis A. Dickman, M.D., Neuroscience Publications, Barrow Neurological Institute, 350 West Thomas Road, Phoenix, Arizona 85013-4496. email: neuropub@mha.chw.edu 